\title{
Unfolding Aqueduct System of Stepwell at Nahargarh, Jaipur
}

\author{
Dhanashri Mirajkar and Nilesh Agarwal \\ D Y Patil School of Architecture, Ambi, Pune, India
}

\begin{abstract}
Nahargarh Fort stands on the edge of the Aravalli Hills overlooking the pink city of Jaipur in Indian state of Rajasthan. The founder of Jaipur city Maharaja Sawai Jai Singh built this Fort in 1734 as a place of retreat on the edge of summit of ridge above the city. This Fort once formed a strong defense ring to the city of Jaipur. Rajasthan is the most water deficient state in the country following short spell of monsoon coupled with erratic behavior and scanty rainfall. Drought is the most frequent disaster recurring in the state. The practice of water conservation is deeply rooted in the sciences of Rajasthan. The state of Rajasthan has an immense range of ancient and ingenious water harvesting systems, one of which is step wells innovated by wise ancient rulers of Rajasthan. The extensive water system of Nahargarh is one of the most significant architectural masterpiece of water collection system. Bawri-Stepwell at Nahargarh which is outside the fort is the ancient source of water, which receives water from the catchment in the surrounding hills and rainwater harvested from the fort complex. A Network of closed catchments connect through small canals and aqueducts. Drains are laid in and outside the fort. Small Canals bring rainwater from the higher reaches of the hills. The Bed of these canals is designed in such a way that it is on a gradient and also at the same time has an undulating course. The underground channels collect rain water and fills the step well without any mechanical energy. This ancient technique of water collection somehow does not receive attention that it deserves. This paper unfolds the ancient wisdom of water carriage system with the help of live survey and literature study done by authors of the paper. This water carriage system can be rejuvenated to fill the stepwell outside the fort and collected water could be the solution on water crisis to some extent.
\end{abstract}

Keywords: Aqueduct, Nahargarh, Water Channel, Step well, Jaipur fort, Water canal, Ancient wisdom, Bawri, Rajasthan

\section{Introduction}

Jaipur considered one of the most prolific examples of a planned city, it exemplifies approaches to city planning, sustainability and spatial manifestation of social fabric through architecture.

Sawai Jai Singh laid the foundation of his new Capital City in 1727A.D. and named it as 'Sawai Jaipur'. It was also known as 'Sawai Jainagar' which later on became popular as 'Jaipur". The establishment of a new Capital City could be justified by two plausible factors - the political dominance which the State of Amber had already acquired in erstwhile Rajputana under the patronage of the Mughal rulers, and the need for an environment that would be suitable as the new Capital of the State. Amber had served as the Capital of Dhoondhar for about six centuries and the Kachhwahas had gained considerable significance during the Mughal period. Though, by the beginning of 18th Century Amber had expanded, having narrow streets, it had become very congested. There was not much scope for further expansion on the existing hilly terrain. To cater the needs of the grown-up State, Sawai Jai Singh chose to build an entirely new city, devoid of the shortcomings of the Amber as a Capital City. The historic Agra-Ajmer highway emerging from the Purana-Ghat or Ghat-Ki-Guni acted as the southern edge of the walled town of Jaipur. 


\section{Foundation of Jaipur City}

The foundation of Jaipur was too an outcome of new economic dimensions. The earlier Capitals of Kachhwahas i.e. Dausa and Amber contain remains of second outer wall surrounding the fields beyond the city walls including the agricultural land, thus indicating the agrarian base of the society. There was a significant economic shift from an agriculture base to trading when the Capital was shifted from Dausa and Amber to Jaipur. The foundation of Jaipur was not spontaneous but it was a planned one and constructed in many successive stages as proved by the contemporary documents and some old maps and plans prepared for planning the City and its environs, out of which many survive still today.

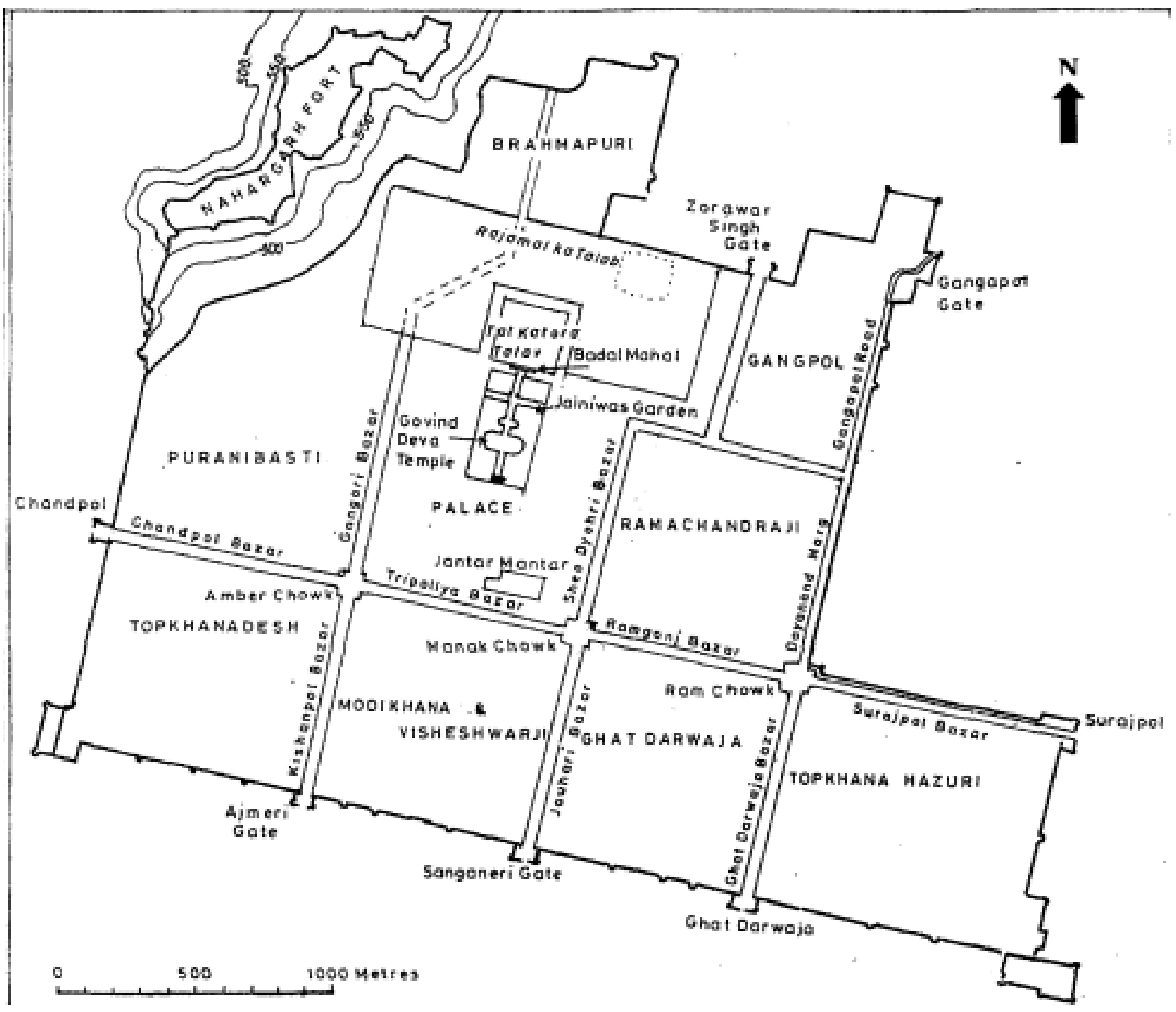

Figure 1 Plan of new capitol Jaipur with Nahargarh built at the apex by Maharaja Sawai Jai Singh

The Maharaja had collected many prints, maps and printed literature from all over the world and after consulting and discussing with his associates and architects he planned his City. The position for the new Capital was so located as to connect it with the Amber fort by the hill range of 'Kali-Khoh', at the apex of whose Sawai Jai Singh built Sudarshangarh (Nahargarh Fort) which commanded his new Capital. ${ }^{[2]}$ Since Jaipur is surrounded by Nahargarh,

Jaigarh, Ganeshgarh and Shankargarh and further by Raghunathgarh and Ambagarh forts on the north and south of Galtaji, these fortifications in turn ensure, at least from three sides, a complete enclosure of the Jaipur City. Thus the city wall of Jaipur was naturally protected from three sides by the hills but the southern city wall is 
without any natural defence fort was a crucial defence against the invading Marathas, and the site for subsequent negotiations between the Marathas and the Jaipur rulers. ${ }^{[3]}$

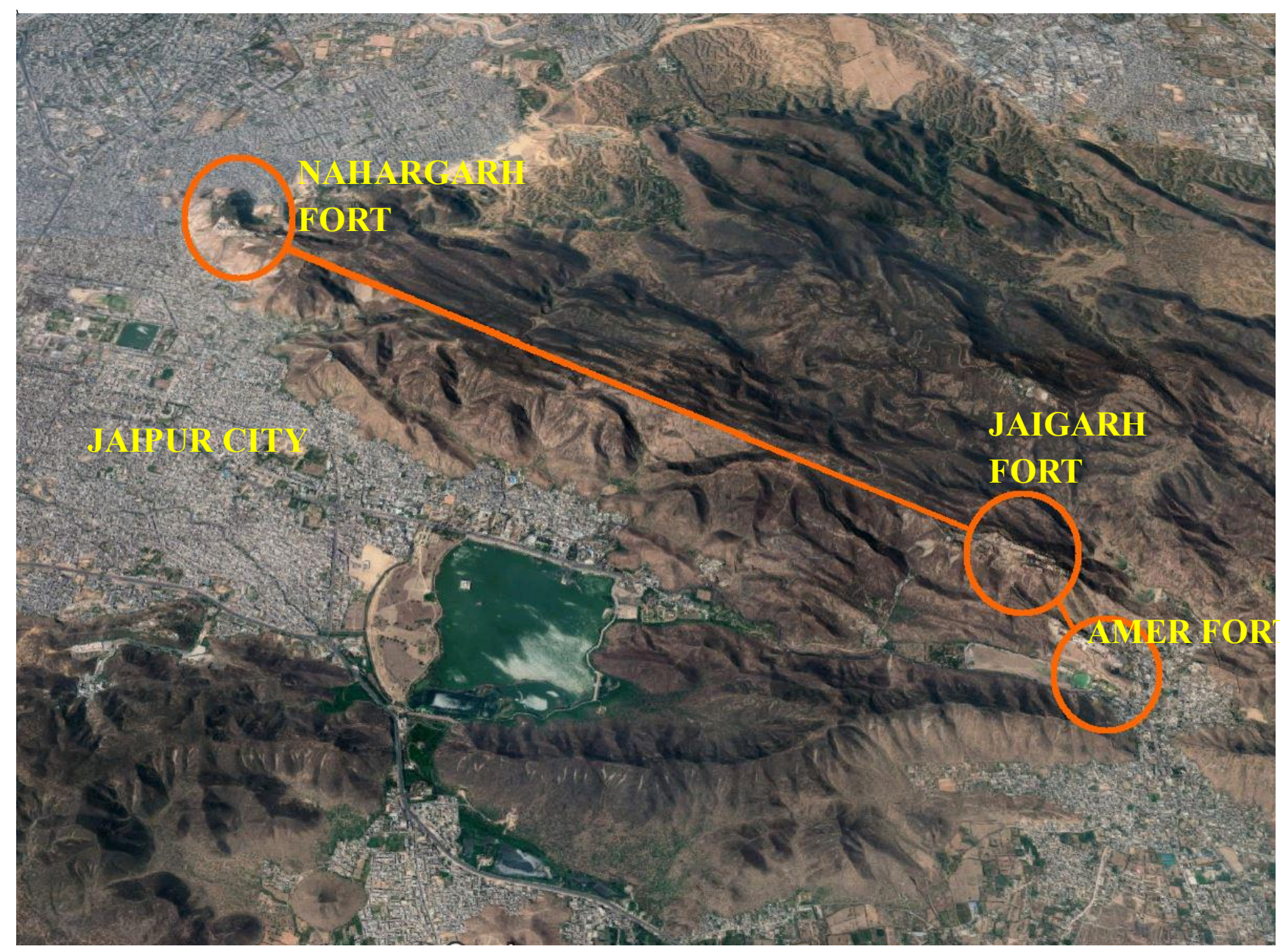

Figure 2 Plan of new capitol Jaipur with Nahargarh Fort, Jaigarh fort and Amer fort

\section{About Nahargarh Fort}

Nahargarh Fort is one of three forts at Jaipur, Amber Fort and Jaigarh Fort, being the other two, once formed a strong defence around the city of Jaipur. Standing tall overlooking the city of Jaipur, Nahargarh Fort is a monumental edifice., Nahargarh Fort was built in 1734 by Maharaja Sawai Jai Singh II, the founder of the city of Jaipur The fort is situated on Cheel ka Teela (Hill of Eagles) and Nahargarh means "abode of tigers".

The fort and stepwell at Nahargarh were built as a defense fort, which was never used. This stepwell design is unique one in that there's no symmetry in kind of steps cut out of the hillside to collect water in.

\section{About Step Well}

Stepwells are certainly one of India's most unusual, but little-known, contributions to architecture. They influenced many other structures in Indian architecture, especially many that incorporate water into their design. Stepwells are wells or ponds in which the water is reached by descending a set of steps to the water level.. They are most common in western India and are also found in the other more arid regions of the Indian subcontinent, 
extending into Pakistan. The construction of stepwells is mainly utilitarian, though they may include embellishments of architectural significance, and be temple tanks. Stepwells are examples of the many types of storage and irrigation tanks that were developed in India, mainly to cope with seasonal fluctuations in water availability.
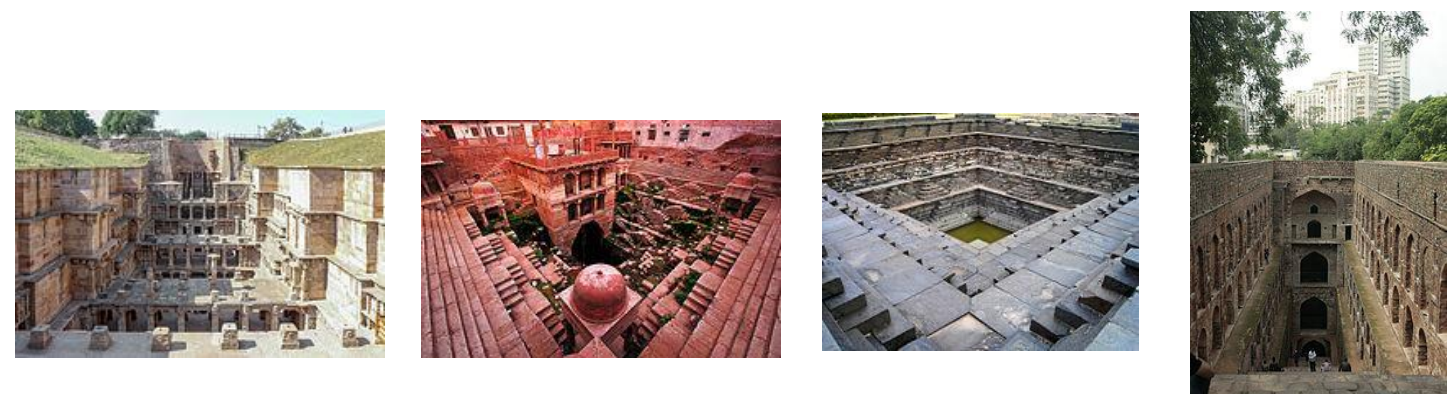

Rani ki vav, Patan, Gujarat

Turji ki Bawri, Jodhpur Step well at Humpi

Agrasen Baoli, New Delhi

Figure 3 Few significant stepwells across the India in various states and region

The stepwell ensures the availability of water during periods of drought. The stepwells had social, cultural and religious significance. These stepwells were proven to be well-built sturdy structures, after withstanding earthquakes A number of surviving stepwells can be found across India, including in Karnataka (North), Gujarat, Rajasthan, Delhi, Madha Pradesh, and Maharashtra. In 2016 a collaborative mapping project, Stepwell Atlas, started to map GPS coordinates and collate information on stepwells. Over 2800 stepwells have so far been mapped.

Apart from the most apparent objective, i.e. serving as a major source of drinking water in hot summers when the soil of other water bodies is rendered ineffective for the retain water, step wells are also often used as a cool refuge from the hot climatic conditions of the state.

Unlike other stepwells in various regions, stepwells within the Nahargarh fort have an asymmetrical design. This Water harvesting structures is an ideal example of ingenuity of Rajasthan Society to innovate for all its needs.

Built In 1734 years ago during the reign of Sawai Jai Singh (1698-1740), the extensive water systems of Nahargarh is one of the most significant features of the fort, which does not receive attention that it deserves. The Catchment area of water for Nahargarh Extends to about $6 \mathrm{kms}$ surrounding the fort. A

Network of six closed catchments connect through small canals and aqueducts and drains are laid in and outside the fort. Small Canals bring rainwater from the higher reaches of the hills. The Bed of these canals is designed in such a way that it is on a gradient and also at the same time has an undulating course. Unlike, Water harvesting system of Fort Jaigarh, Nahargarh Has two large step wells (Baoli) and a smaller step well called as "Kund". The stepwells receive water from the catchment in the surrounding hills while, the Kund receives rainwater harvested from the fort complex.

\section{Stepwell at the entry of Nahargarh}

This huge stepwell was built to collect and conserve rain water coming through the canals laid out on the hills of Nahargarh. Small chambers were constructed in the canals at intervals to filter the impurities in the water. A special water purification system was set up near the step well to purify the rain water in multiple phases. To understand this water collection system, authors of this paper have done a detail live study of this step well on 5th December 2019. The study revealed that the rain water flowing from the upper parts of the hill gets collected 
to lower contours, where this step well is located. Small canals bring the water from higher reaches of hill. The rain water collected from the upper levels of the mountain gets stored into the two step wells which could be used for drinking and other activities throughout the year. Through this live study, authors understood the water collection system of step well in detail

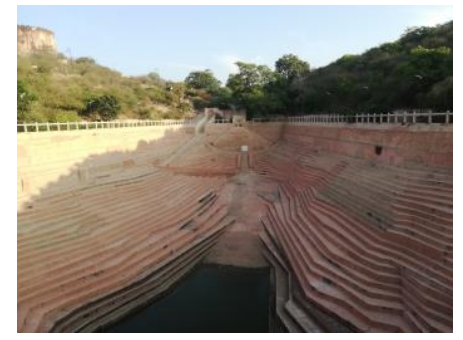

A - Stepwell at entry of Fort
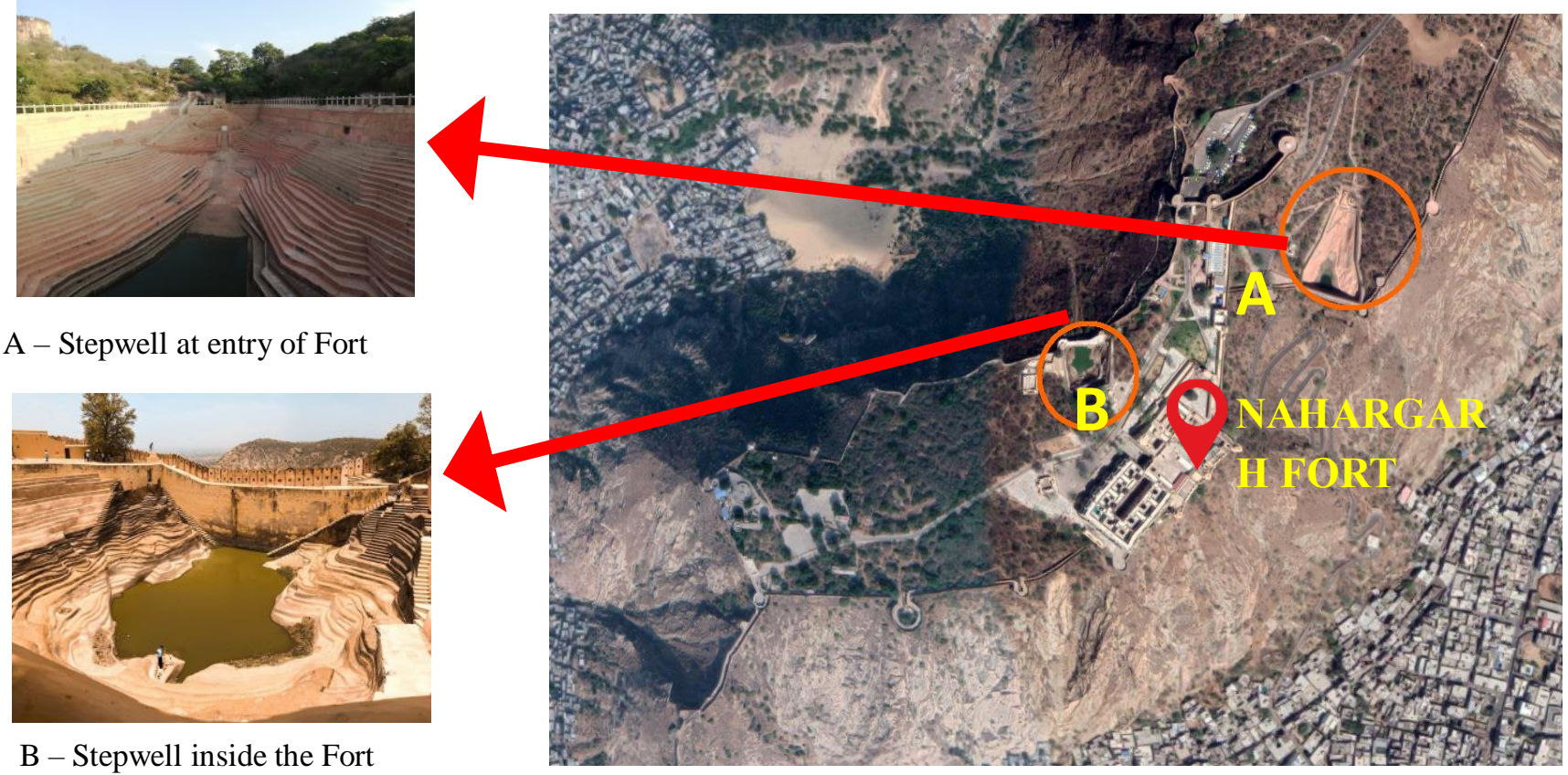

B - Stepwell inside the Fort

Figure 4 Nahargarh Fort showing two step wells one at entry and another inside the Fort

\section{Understanding water collection system}

A network of six close catchments connect though small canals and aqueducts and drains are laid in outside of the Fort. Small canals bring the water from the high reaches of the mountain.

The bed of these canals is designed in such a way that it is on a gradient and also at the same time has a $\mathrm{n}$ undulating course. The catchment area of water at Nahargarh extends to $6 \mathrm{~km}$ surrounding the Fort and these canals carry water from these catchment areas. These 2'6" wide underground canals carry rain water from hill tops. The canals run underground and have a height of approximately 3 feet below ground level. Canal starts at the apex of the hill. Canal gets divided into two branches one proceeds to stepwell at entry and other proceeds to the stepwell inside the fort. At this junction a slit is provided at ground level to insert the stone slab which could stop the flow of water towards the stepwell at entry. 


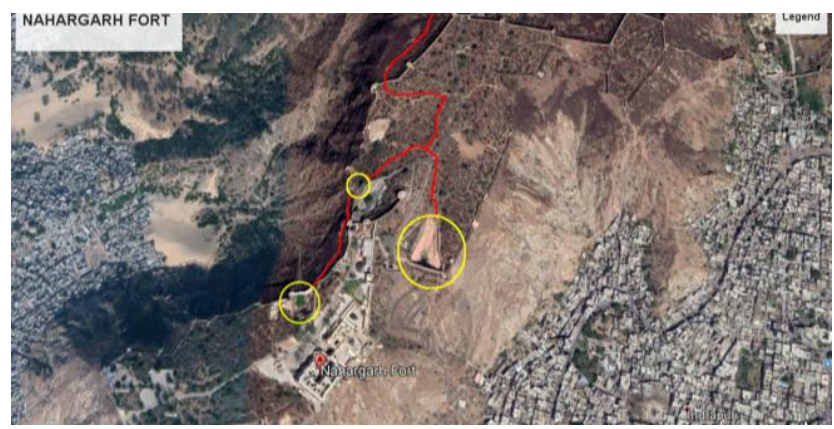

Figure 5 Red line shows the travel path of rain water collected from upper level of the mountains till the two stepwells of Nahargarh

The gradient of the hill is used to channel the flow of the water. A special water purification system was set up near the step well to purify the rain water in multiple phases. An elaborate swirling mechanism to ensure that the gush of water can be regulated, and that the structure does not suffer damage in case of the heavy flow. The water then leads to a portion of the hill that is carved to form a tank.

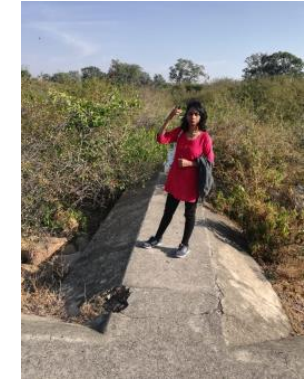

1 Underground canal

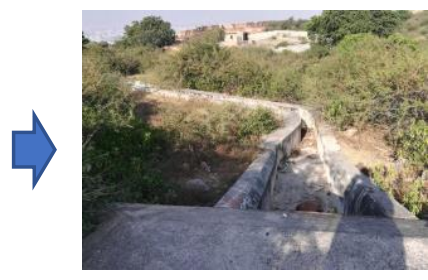

2 To stepwell

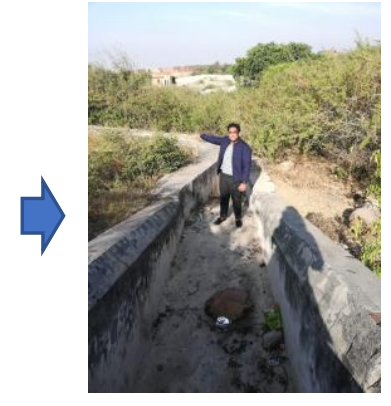

3 Open canal

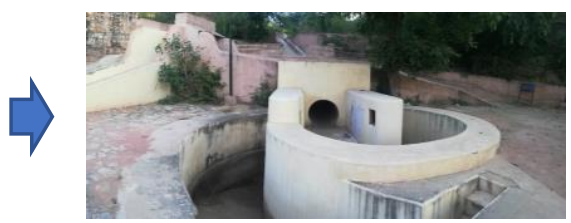

4 Filtration plant

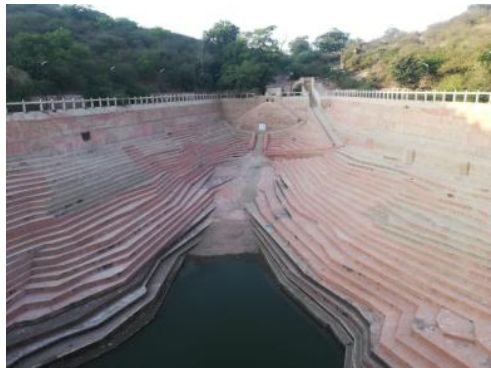

7 Final destination - Stepwell

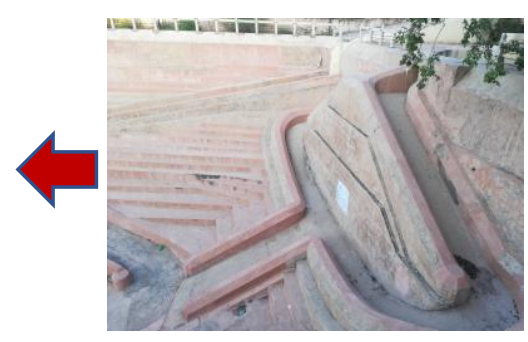

6 Gushing water way

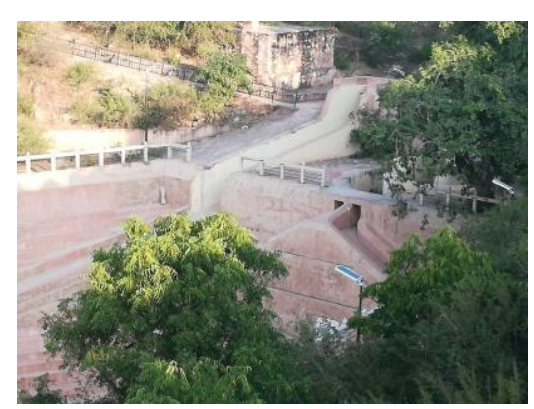

5 Outlet after filtration

Figure 6 Live study done by authors revealed the path of water from the source (1 to 7) - hill apex to the destination - Stepwell at the entry of Nahargarh

\section{A. Stepwell at the entry of the Fort}

Figure 6 shows the journey of rain water through an underground aqueduct to the destination via an open channel which runs along the gradient of the mountain and carries rain water down towards the step well at lower contours.

The channel seen in Image 1 of Figure 6 is an underground aqueduct which carries rain water collected from the hill tops. The underground channel is further bifurcated into two different directions as, one proceeds towards the step well at the entry of the fort while another proceeds to the step well inside the fort. This gushing water runs along the slope via an open channel as seen in Image 2 and enters to a swirling mechanism of water purification system placed near to the step well at the entry as seen in Image 4. This elaborate swirling 
mechanism is designed in such a way that it ensures that the gush of water can be regulated, and that the structure does not suffer damage in case of the heavy flow. The water then lead to a portion of the hill that is carved to form a tank as seen Image 7, which is an unusual asymmetrical step well. This stepwell water used to serve the dry region for daily water needs.

\section{B. Stepwell inside the Fort}

Figure 7 shows the journey of the rain water till the stepwell which is constructed inside the Fort. The bifurcated underground aqueduct leads towards the stepwell inside the fort via an open channel at ground surface through hillocks. This second branch meets to a filtration chamber where all the impurities set down and clean water flows towards the underground canal which opens to the exterior wall of the fort. This canal opens in to the exterior wall of fort, water then gushes through open canal at the edge of the hill, leading to the step well inside the fort along the gradient of the hill. In Figure 7, image 1 shows the bifurcation of the underground aqueduct which collects the water from the source which is at hill top. Image 2 shows the chamber in image 3 where all impurities settle down and water gets carried through a canal.

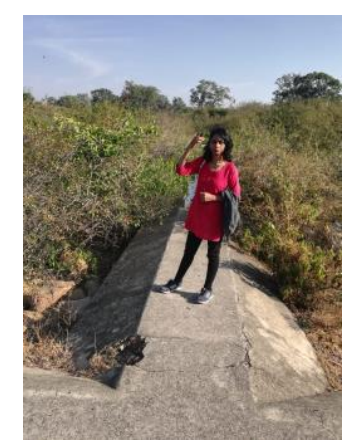

1 Underground canal

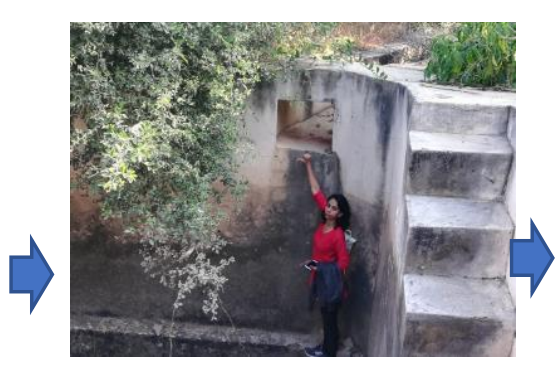

2 Cleaning chamber

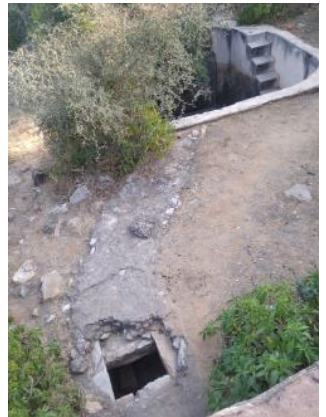

3 Waterway below ground

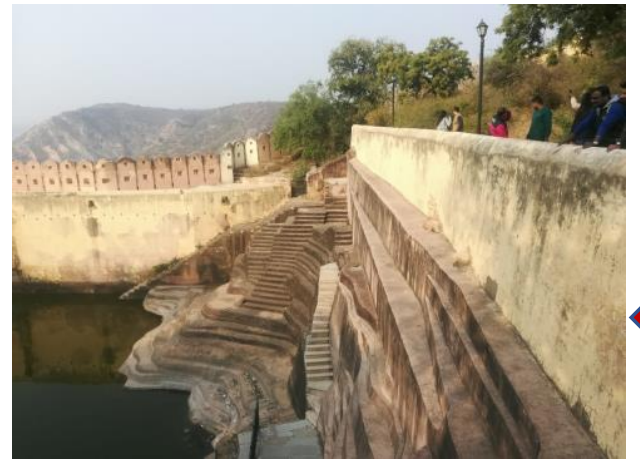

7 Final destination- Stepwell

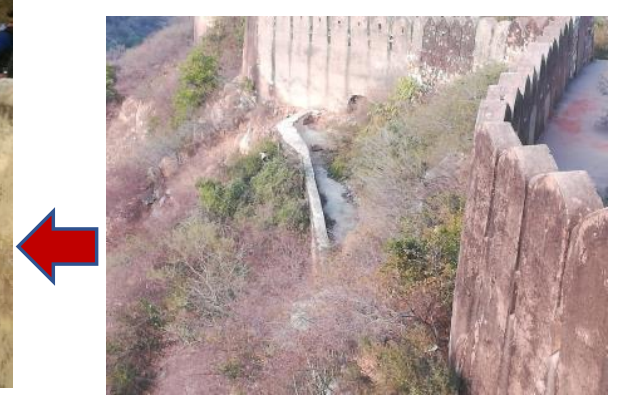

6 Open canal towards fort

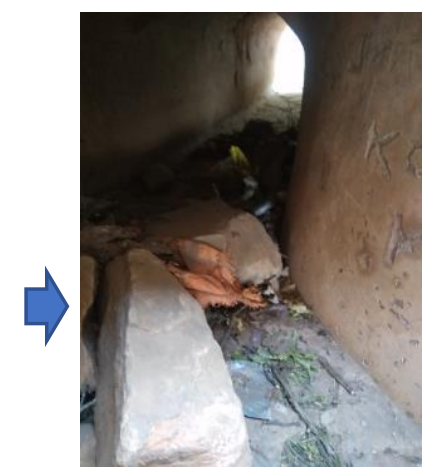

4 Towards fort

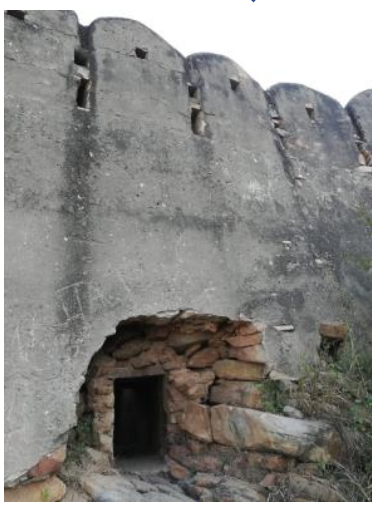

5 Water outlet

Figure 7 Live study done by authors revealed the path of water from the source (1 to 7) - hill apex to the destination - Stepwell inside the Nahargarh

Image 4 in Figure 7 shows the underground canal which opens on the outer surface of the Fort wall as seen in Image 5 This opening brings water which further gets carried via an open canal as seen in Image 6 along the mountain gradient and leads towards the stepwell inside he Fort as seen in Image number 7 in Figure 7.

\section{Discussion}

This water collection system at Nahargarh is more than 280 years old. It is a useful water source at hill top which once served the civilization settled in the Fort. These step wells were made for public utility thus played 
an important role in social sustainability. This water collection causes no loss of water. All the water collected from hill top runs through channels and gets collected in step wells for maximum utility. This water collection system requires very less man power to handle it. This traditional water system is kept small enough to be easily managed and controlled by pooling the capital, labour and technical system at community scale.

ISuch type of water collection system could be rejuvenated if properly maintained. The system is evolved in direct response to the geological and geographical conditions of the region. This system requires no electricity, motor pump or diesel or any other mechanical power to run. It runs on the basis of the pressure created due to gravitational force. The filtration plant also requires no mechanical forces to purify the water. It is designed in such a way that it removes impurities with the help of its own form of design. The whole water collection system requires no maintenance or repair cost. The system is sustainable ecologically, economically as well as society. A very less water could be now collected due to reduced rain fall as denseness of trees is reduced. The filtration chamber is not cleaned since many years and a dense vegetation grown near and inside the chamber. At the bifurcation point, the water way leading towards the stepwell at the entry of Nahargarh Fort is blocked with the help of concreting which allows not the water to flow into the step well. Open channels at ground level which carry water are blocked due to garbage fill.

Jaipur ranks 10th among Indian megacities with a population of 3.1 million. The city's economy is primarily based on trading, administration, tourism activities, \& local handicrafts industries. Jaipur is a popular tourist destination, with about 3000 tourists visiting the city daily. Jaipur depended on the Ramgarh Dam as its surface water source throughout the 1900s, but this became a non-viable source in the late-1980s/early-1990s, leading to a shift to complete dependence on groundwater \& thus, a rapidly depleting aquifer. Jaipur is currently experiencing growing water scarcity and diminishing drinking water sources. Jaipur relies extensively on groundwater and a single surface water source, the Bisalpur Dam, which is located $120 \mathrm{~km}$ southwest of Jaipur $\&$ is shared with Ajmer and Tonk District villages. There is a lack of adequate water supply and demand accounting, both in terms of government water supply and private water supply. In addition to water scarcity, degradation in quality of both surface and groundwater sources is of great concern. Jaipur is located in the semiarid zone of India, which is characterized by high temperatures, low rainfall, and a mild winter. The average annual rainfall of Jaipur is about $600 \mathrm{~mm}$. The Old City continued to benefit from the original natural water systems in place until the 1930s when the population of Jaipur exceeded the capacity of the Old City. The city soon had to turn to reservoirs located outside the immediate reaches of the city. Compounded by a lack of infrastructure (e.g., sewage systems, water piping, or drainage systems) \& rapid growth, which defied any unified government planning, Jaipur's water security and supply began to deteriorate.

\section{Current water supply and management}

The water supply from the government is intermittent and the average duration of running water is $90-120$ minutes per day. General inadequacy in water availability can be found in: - calculations of supply and demand that reveal deficits in government water supply - high unaccounted for water losses - drops in supply pressure due to large quantities of water released in short durations or the depletion of groundwater affecting pressure in tube wells - issues with water metering and fees. It is difficult to make accurate estimates for water demand due to the presence of many tourists, large migration fluxes, high unaccounted for distribution losses, and inadequate water metering for customers.

The forts built around Jaipur and its original layout exhibit traditional water harvesting techniques. Nahargarh Fort has many wide water channels and two step wells, with the largest tank. Water channels were built in the Aravalli catchment and conveyed water to Nahargarh Fort. Rainwater capture and storage systems are also present at Amer and Jaigarh Fort. 
This paper revealed the water carriage system of the two step wells at Nhargarh through a live study. If such traditional water supply system rejuvenated, Jaipur city can rely on this water and it can reduce the gap between water supply and water demand of the city. Conservation of heritage for Adoptive reuse of existing structure is the smartest intervention for a city to proceed towards the Smart City. It can help to reduce carbon footprint by retaining the "embodied energy" of existing structure which is of a great heritage value also. This research can be used as educational resources for students, technicians, professionals, resources well as well as general public. At the same time, it can attract tourists to recur the cost of repair and maintenance.

\section{Conclusion}

This ancient water system is highly sustainable as it improved the quality of human life whilst living within the carrying capacity of the ecosystem. It is evolved in direct response to geo graphical and geological conditions of the region thus becomes ecologically sustainable. It relies on only gravitational force for carrying the water from source to the destination thus becomes economically sustainable. The natural benefits of mountains are used efficiently as the aqueduct contains a fully gravitational flow, flawless network of the channels, properly spaced outlet and highly efficient purification plant.

The system could cater the tourist destination activities in the Nahargarh fort as well as towns at the hill foot without involving electricity and other traditional resources. Jaipur city and nearby towns could have permanent and adequate supply of drinking water collection and storage system which is free of cost. It can generate the employment to local people through tourism and restoration of step wells.

It is a free of cost, sustainable source, by rejuvenating or replicating or adopting this system, very well water source as well as an employment can be assigned.

\section{Limitations}

This research took an attempt to reveal an ignored ancient wisdom which should be understood by new generations. The research was limited to understand the underground water collection system. The rain water from catchment areas of hilly mountains is collected and carried through underground water canal system to fill two stepwells in and outside the Nahargarh fort at Jaipur. The live survey was done till the point of reach on the hilly regions. Original source on mountains could not be marked as it is situated on high peaks of hill.

\section{Acknowledgements}

Authors express their gratitude to Shrinit Mirajkar, Dipayan Sarkar and Aviraj Pulickal for their kind help in preparing the presentation video for this research paper.

\section{References}

https://shodhganga.inflibnet.ac.in/bitstream/10603/55683/10/10_chapter\%202.pdf

https://www.sahapedia.org/jaipur-history-and-architecture

Roberts K., Reiner M., and Gray K., Northwestern University Research in Jaipur in Summer 2013 January 2014, Water Scarcity in Jaipur, Rajasthan, India

TORASKAR, V. V., Prof. Gouri .A. MHETAR, G. A., PATIL M. R., 2017, Study of Architecture and Planning of Jaipur City in context with Vastushastra, ISSN 0974-3154 Volume 10, Number 1 (2017) () International Research Publication House http://www.irphouse.com

The authors of this paper have done a live case study to understand rain water collection system. All the images clicked by authors in this survey on 25th December 2019. 